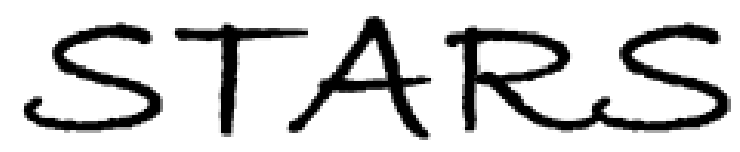

University of Central Florida

STARS

$1-1-2009$

\title{
Photothermal effect in narrow band gap PbTe semiconductor
}

\author{
Z. Dashevsky \\ V. Kasiyan \\ S. Asmontas \\ J. Gradauskas \\ E. Shirmulis
}

See next page for additional authors

Find similar works at: https://stars.library.ucf.edu/facultybib2000 University of Central Florida Libraries http://library.ucf.edu

This Article is brought to you for free and open access by the Faculty Bibliography at STARS. It has been accepted for inclusion in Faculty Bibliography 2000s by an authorized administrator of STARS. For more information, please contact STARS@ucf.edu.

\section{Recommended Citation}

Dashevsky, Z.; Kasiyan, V.; Asmontas, S.; Gradauskas, J.; Shirmulis, E.; Flitsiyan, E.; and Chernyak, L., "Photothermal effect in narrow band gap PbTe semiconductor" (2009). Faculty Bibliography 2000s. 1455. https://stars.library.ucf.edu/facultybib2000/1455

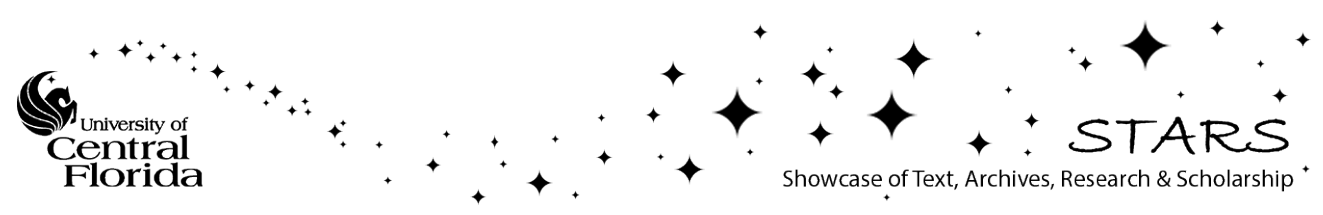




\section{Authors}

Z. Dashevsky, V. Kasiyan, S. Asmontas, J. Gradauskas, E. Shirmulis, E. Flitsiyan, and L. Chernyak 


\section{Photothermal effect in narrow band gap PbTe semiconductor}

Cite as: J. Appl. Phys. 106, 076105 (2009); https://doi.org/10.1063/1.3243081

Submitted: 13 July 2009. Accepted: 08 September 2009 . Published Online: 13 October 2009

Z. Dashevsky, V. Kasiyan, S. Asmontas, J. Gradauskas, E. Shirmulis, E. Flitsiyan, and L. Chernyak

\section{ARTICLES YOU MAY BE INTERESTED IN}

Enhanced exciton photoluminescence in the selectively Si-doped $\mathrm{GaAs} / \mathrm{Al}_{X} \mathrm{Ga}_{1-X} \mathrm{As}$ heterostructures

Journal of Applied Physics 108, 063522 (2010); https://doi.org/10.1063/1.3483240

Selective thermal terahertz emission from GaAs and AlGaAs

Applied Physics Letters 105, 091601 (2014); https://doi.org/10.1063/1.4894539

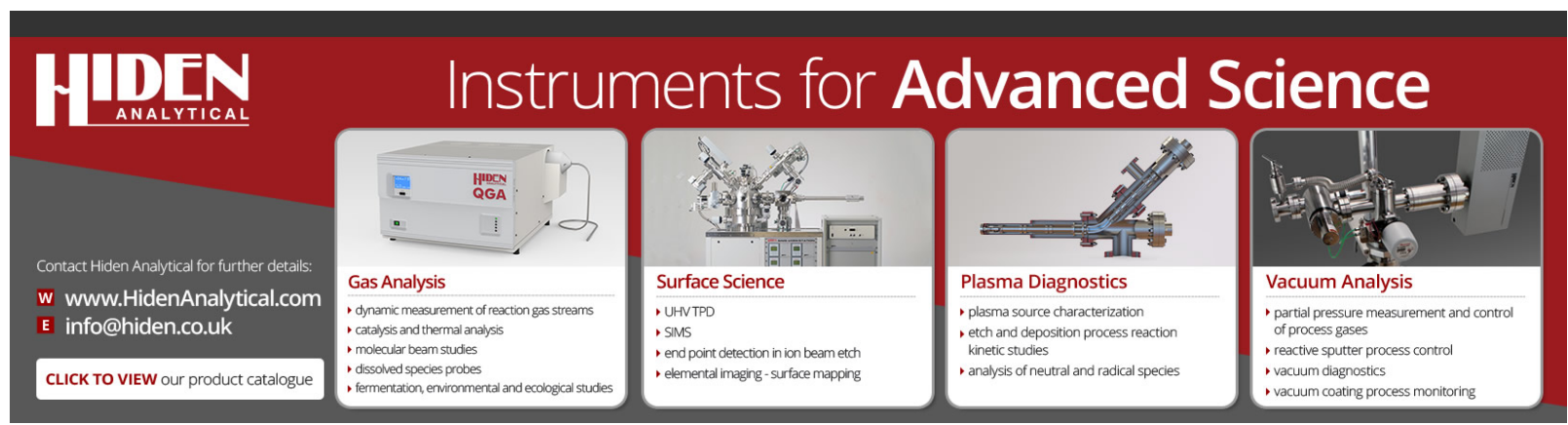




\title{
Photothermal effect in narrow band gap PbTe semiconductor
}

\author{
Z. Dashevsky, ${ }^{1}$ V. Kasiyan, ${ }^{1}$ S. Asmontas,${ }^{2}$ J. Gradauskas,${ }^{2}$ E. Shirmulis, ${ }^{2}$ E. Flitsiyan, ${ }^{3}$ \\ and L. Chernyak ${ }^{3, a)}$ \\ ${ }^{1}$ Department of Materials Engineering, Ben-Gurion University of the Negev, Beer-Sheva 84105, Israel \\ ${ }^{2}$ Semiconductor Physics Institute, A. Gostauto 11, Vilnius 2600, Lithuania \\ ${ }^{3}$ Department of Physics, University of Central Florida, Orlando, Florida 32816-2385, USA
}

(Received 13 July 2009; accepted 8 September 2009; published online 13 October 2009)

In this paper we report the observation of photothermal effect in PbTe $p$ - $n$ junction. The effect is expressed in photosignal generation due to illumination by $100 \mathrm{~ns}$ pulse $\mathrm{CO}_{2}$ laser with photon energy less than PbTe forbidden gap. (C) 2009 American Institute of Physics.

[doi:10.1063/1.3243081]

Lead telluride $(\mathrm{PbTe})$ is a narrow band gap semiconductor with an energy gap $E_{g}=190 \mathrm{meV}$ at $T=0 \mathrm{~K}$. PbTe and a wide range of its solid solutions represent a group of materials that are extensively used in different fields of opto- and microelectronics, thermoelectricity, and even as gas sensors. ${ }^{1}$ Because the band gap of PbTe corresponds to the infrared (IR) spectral region of 3-5 $\mu \mathrm{m}$, a PbTe $p-n$ junction is often considered as a promising middle IR-detector. ${ }^{2}$ Recently we reported the observation of pyroelectric effect (PRE) in $\mathrm{PbTe}$ $p$ - $n$ junction. ${ }^{3}$ This effect is due to a temperature-dependent electric dipole in a nonpolar semiconductor. The junction was illuminated by modulated $(4-200 \mathrm{~Hz}) \mathrm{CO}_{2}$ laser beam with $\sim 1 \mathrm{~W} / \mathrm{cm}^{2}$ intensity. The pyroelectric signal with the magnitude of $\sim 10-20 \mu \mathrm{V}$ and polarity, which changed in the dark phase, has been observed.

In this paper we report a photosignal (PS) from $\mathrm{PbTe} p$ - $n$ junctions under $\mathrm{CO}_{2}$ single-pulse (100 ns duration) laser excitation. The PS shape differs from that previously reported by us in Ref. 3: After laser illumination the PS decreases to zero on microsecond scale without changing its polarity.

Two types of $p-n$ junctions have been studied in this work. These junctions differ by the method used to create the $n$-region "pocket" within the $p$-type PbTe ingot. While the first method used $\mathrm{In}_{4} \mathrm{Te}_{3}$ gas diffusion [thermally diffused junctions (TDJs)], the other employed ion implantation [implanted junctions (IJs)]. Schematics of both types of $p-n$ junctions are presented in Fig. 1.

$\mathrm{PbTe}$ crystals were grown by a Czochralski technique. ${ }^{4}$ $\mathrm{A}\langle 100\rangle$-oriented PbTe-seed was used for growth. To prevent decomposition of the melt, liquid encapsulation by about 1-cm-thick molten $\mathrm{B}_{2} \mathrm{O}_{3}$ layer was employed. The crystals were grown with excess of Te (up to 0.3 at. \%), which leads to acceptor point defects ( $\mathrm{Pb}$ vacancies) with zero activation energy. ${ }^{4}$ These defects were quenched-in by sufficiently rapid cooling, to inhibit their contribution to the electrical conductivity. The Hall effect was employed for direct measurements of free carrier concentration. The acceptor concentration, $N_{a}$, in as-grown crystals was $\approx 10^{18} \mathrm{~cm}^{-3}$. The saturation mobility, $\mu_{\text {sat }}$, was $10^{6} \mathrm{~cm}^{2} / \mathrm{V} \mathrm{s}$ at $4.2 \mathrm{~K}$, which indicates a high quality of $\mathrm{PbTe}$ crystals. ${ }^{5}$



Rectangular wafers $\left(20 \times 10 \times 1 \mathrm{~mm}^{3}\right)$ used in this research were cut from a single-crystal ingot. One of the sides of these wafers has been successively polished mechanically and electrochemically. ${ }^{5}$ Thermally diffused doping was accomplished by exposing the sample to indium from $\operatorname{In}_{4} \mathrm{Te}_{3}$ gaseous source. The concentration of In-dopant was in the $0.1-0.5$ at. \% range and was varied by changing the exposure time $(1-5 \mathrm{~h})$ and annealing temperature (from 500 to $600{ }^{\circ} \mathrm{C}$ ). Unique properties of In-doped $\mathrm{PbTe}$ are related to the effect of Fermi level pinning. ${ }^{6}$ In the latter case, a stable free carrier concentration is achieved, independent of indium concentration variation in the sample. At $4.2 \mathrm{~K}$, the Fermi level is pinned at $70 \mathrm{meV}$ above the conduction band edge, giving rise to the electron density of $6 \times 10^{18} \mathrm{~cm}^{-3}$.

For IJ structures, an oxide layer has been electrochemically formed and subsequently patterned on a polished wafer side [see Fig. 1(b)]. The samples were uniformly implanted by $200 \mathrm{keV} \mathrm{Zn}$ ions with a dose of $1 \times 10^{16}$ ions $/ \mathrm{cm}^{2}$. This allowed intrinsic diffusion of implantation-induced Te vacancies (donors in $\mathrm{PbTe}$ ) leading to homogeneous electron concentration of $\sim 6 \times 10^{18} \mathrm{~cm}^{-3}$ across a $4-\mu$ m-thick sample. ${ }^{5}$

To determine location of $p$ - $n$ junction within the sample, a method for measuring the local Seebeck coefficient along the surface of the doped crystal was used. ${ }^{5}$ Seebeck coefficient variations were measured along a direction normal to the external surface and the $p-n$ junction depth was obtained

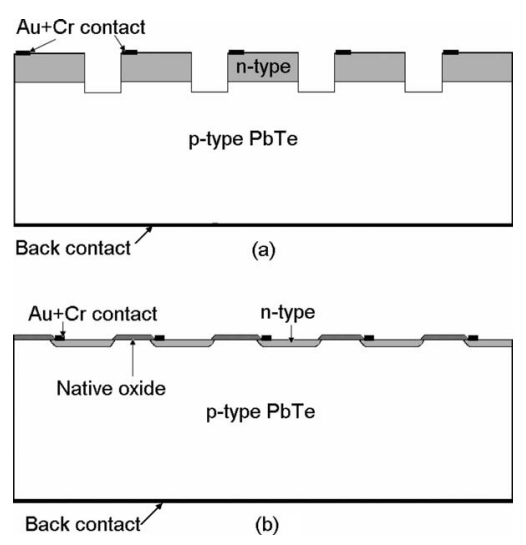

FIG. 1. Schematic view of the $p-n$ junction diode array. (a) Mesa columns of TDJ. (b) The planar array of IJs, formed by ion implantation through the windows in the oxide layer. 
TABLE I. Main properties of PbTe diodes.

\begin{tabular}{lcccc}
\hline \hline Type of diode & $\begin{array}{c}\text { Temperature } \\
(\mathrm{K})\end{array}$ & $\begin{array}{c}\text { Resistance at zero bias, } R_{0} \\
(\Omega)\end{array}$ & $\begin{array}{c}\text { Capacitance, } C \\
(\mathrm{nF})\end{array}$ & $\begin{array}{c}R_{0} C \text { time constant, } \tau \\
(\mathrm{s})\end{array}$ \\
\hline TDJ & 80 & $1.30 \times 10^{5}$ & 7.00 & $9.1 \times 10^{-4}$ \\
TDJ & 110 & $1.10 \times 10^{4}$ & 6.35 & $6.98 \times 10^{-5}$ \\
TDJ & 140 & 540 & 5.7 & $3.08 \times 10^{-6}$ \\
TDJ & 180 & 59 & 5.5 & $3.25 \times 10^{-7}$ \\
IJ & 80 & $1.24 \times 10^{4}$ & 14.4 & $1.79 \times 10^{-4}$ \\
IJ & 100 & $1.00 \times 10^{4}$ & 14.2 & $1.42 \times 10^{-4}$ \\
IJ & 140 & 103 & 13.9 & $1.43 \times 10^{-6}$ \\
IJ & 180 & 14.6 & $\cdots$ & $\cdots$ \\
\hline \hline
\end{tabular}

from a change in Seebeck coefficient polarity. While for IJ crystals a junction was located at the depth of several microns under the PbTe surface, for TDJ crystals the depth of about $70 \mu \mathrm{m}$ counting from the top surface was obtained.

Capacitance-voltage $(C-V)$ and current-voltage $(I-V)$ curves were measured over 12-200 $\mathrm{K}$ temperature range. The investigated samples were placed in a closed-cycle Hegas cryostat under the pressure of $\sim 10^{-7}$ Torr. The temperature stability was at the level of $0.02 \mathrm{~K}$ above $100 \mathrm{~K}$. I-V characteristics of $p-n$ junctions were obtained by varying bias voltage between -1 and $+0.3 \mathrm{~V}$ with measurements being taken every $0.2 \mathrm{mV}$. A QuadTech $1920 L C R$-meter was used for $C-V$ measurements. The capacitance was measured using an alternating signal of $20 \mathrm{mV}$ at $1 \mathrm{MHz}$, with reverse bias voltage between 0 and $1 \mathrm{~V}$ with measurements taken every $2 \mathrm{mV}$.

The junction was illuminated by $Q$-switched $\mathrm{CO}_{2}$ laser beam with the wavelength of $9.5 \mu \mathrm{m}$, pulse duration of 100 $\mathrm{ns}$, and maximum intensity of about $0.1 \mathrm{MW} / \mathrm{cm}^{2}$. The laser beam was focused by a $\mathrm{ZnSe}$ lens down to a diameter of $\sim 1 \mathrm{~mm}$. The observed photoelectric response was measured as a function of temperature, reverse bias voltage, and laser beam intensity. The temporal response from a $p-n$ junction has been measured by Tektronix differential preamplifier ADA400A and displayed using Tektronix e-Scope TDS 3054B. The laser pulse duration was measured using a $\mathrm{Ge}: \mathrm{Au}$ detector.

$I-V$ and $C-V$ characteristics of TDJ and IJ structures are presented in Ref. 7. In this paper, the values for capacitance and resistance at zero bias $\left(R_{0}\right)$ are summarized in Table I for the $80-180 \mathrm{~K}$ temperature range. The $R C$ time constant $(\tau$ $\left.=R_{0} \times C\right)$ is also given in Table $\mathrm{I}$. The linearity of $C^{-3}$ versus bias indicates that both types of junctions are linearly graded. ${ }^{7}$ While for TDJ structure the rectifying properties are observed up to $180 \mathrm{~K}$, the IJ structure exhibits $p$ - $n$ characteristics up to $140 \mathrm{~K}$. The experimental $I-V$ curves have been fitted with Schokley formula,

$$
I=I_{0}\left[\exp \left(\frac{e V}{n k T}\right)-1\right]
$$

where $I_{0}$ is the saturation current, $n$ is the ideality factor; $k$ is the Boltzmann constant, and $T$ is the absolute temperature. At $T \geq 80 \mathrm{~K}$ the ideality factor $n$ is close to 2, which demonstrates that the dominant generation-recombination process in $p$ - $n$ junction is similar to that in the Schottky barrier on PbTe epitaxial film. ${ }^{8}$ At $80 \mathrm{~K}$, the barrier height $e V_{0}$ for both types of diodes is close to the energy gap $E_{g}$ (for $\mathrm{PbTe}$, $E_{g} \approx 210 \mathrm{meV}$ at $80 \mathrm{~K}$ ) and $e V_{0}$ decreases sharply with increasing temperature. For TDJ structure, $e V_{0}$ is on the level of $80 \mathrm{meV}$ at $180 \mathrm{~K}$. For IJ structure, the barrier flattens at $140 \mathrm{~K}$.

The PS for both types of $p-n$ junctions, compared to that from Ge:Au detector, is displayed in Fig. 2 at 90 K. Note that the polarity of $p-n$ junction PS is consistent with that for photovoltaic effect, which could be induced in $p-n$ junction under proper illumination. Figure 2 also shows the PS predicted in accordance with Eq. (2) (see below) for TDJ structure.

The low temperature $(90 \mathrm{~K})$ photoresponse as a function of bias for TDJ structure is shown in Fig. 3(a). The PS disappears at the forward bias close the barrier height $e V_{0}$. The PS as a function of the incident radiation power $P / P_{0}\left(P_{0}\right.$ $=1 \mathrm{~kW})$ at $90 \mathrm{~K}$ is shown in Fig. 3(b) for TDJ structure. The PS grows over the whole power range and approaches saturation at the maximum power. The PS versus temperature for two types of structures is presented in Fig. 4. Note that the PS maximum decreases with increasing temperature due to decreasing barrier height. In TDJ structure, for example, the PS persists for up to $180 \mathrm{~K}$, consistent with observation of rectifying properties for this type of $p$ - $n$ junction.

The model that accounts for the effect of PS generation (also known as photothermal effect) consists of the following steps:

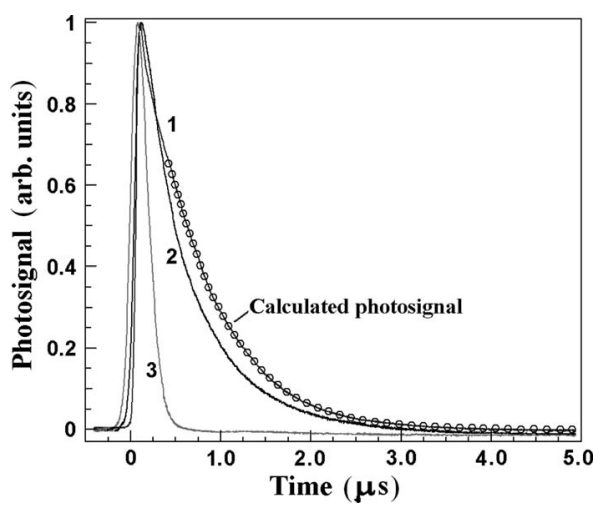

FIG. 2. PS for PbTe $p-n$ junction structures [(1) TDJ, (2) IJ] and reference detector Ge:Au (3) at $90 \mathrm{~K}$. The PS, calculated in accordance with Eq. (2), is shown for TDJ. 

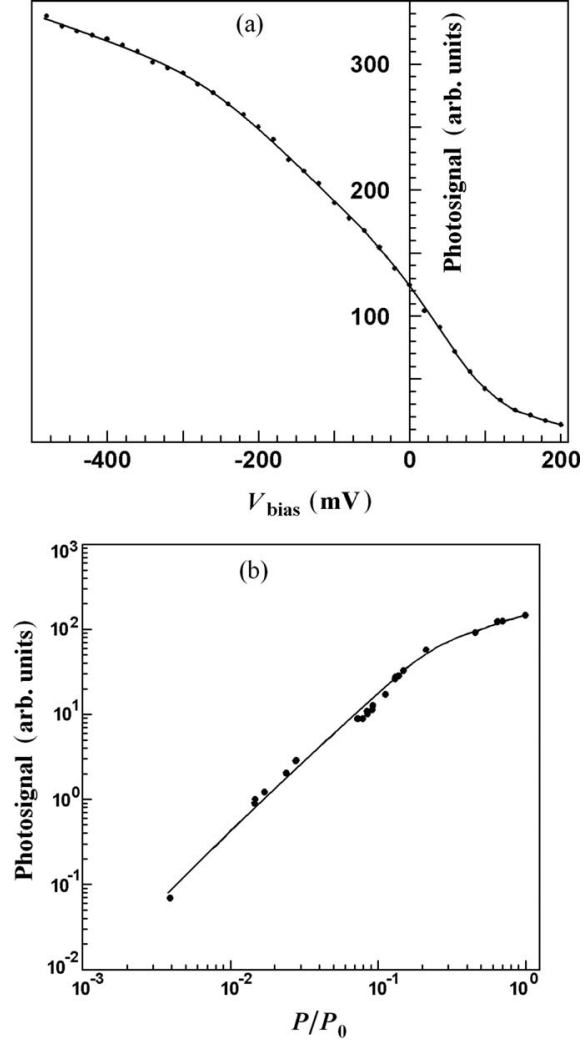

FIG. 3. (a) PS from TDJ structure at $T=90 \mathrm{~K}$ vs bias voltage. (b) PS from TDJ structure at $T=90 \mathrm{~K}$ as a function of $\mathrm{CO}_{2}$ laser intensity.

- strong laser pulse (IR-photons) absorption on free carriers [in $\mathrm{PbTe}$, the absorption coefficient on free carriers is $\sim 3 \times 10^{4} \mathrm{~cm}^{-1}$ at $\lambda \approx 10 \mu \mathrm{m}$ and $n \sim 5$ $\times 10^{18} \mathrm{~cm}^{-3}$ (Ref. 9)] induces heating of the electron system in a $2-3-\mu \mathrm{m}$-thick layer;

- heat transfer from the "hot electrons" to the phonon system within a characteristic time of $\sim 10^{-11} \mathrm{~s}$ (Ref. 10);

- localized temperature rise and consequent thermal generation of nonequilibrium electron-hole pairs that diffuse toward $p$ - $n$ junction;

- separation of electron-hole pairs on $p-n$ junction built-in electric field (this effect is reminiscent of $p-n$ junction photovoltaic effect);

- recombination of electron-hole pairs after laser pulse.

The back PS front, which is associated with recombination of electron-hole pairs, is described as

$$
V(t)=V_{\max } \exp \left(-\frac{t}{\tau}\right),
$$

where $V_{\max }$ is the PS amplitude, $t$ is the current time, and $\tau$ is the decay constant.

Fitting the experimental results with Eq. (2) gave the decay constant of $\sim 0.5 \mu$ s for TDJ structure (see Fig. 2).

We observed the photothermal effect in the narrow band gap $\mathrm{PbTe} p$ - $n$ junctions under far-IR $\mathrm{CO}_{2}$-laser irradiation.
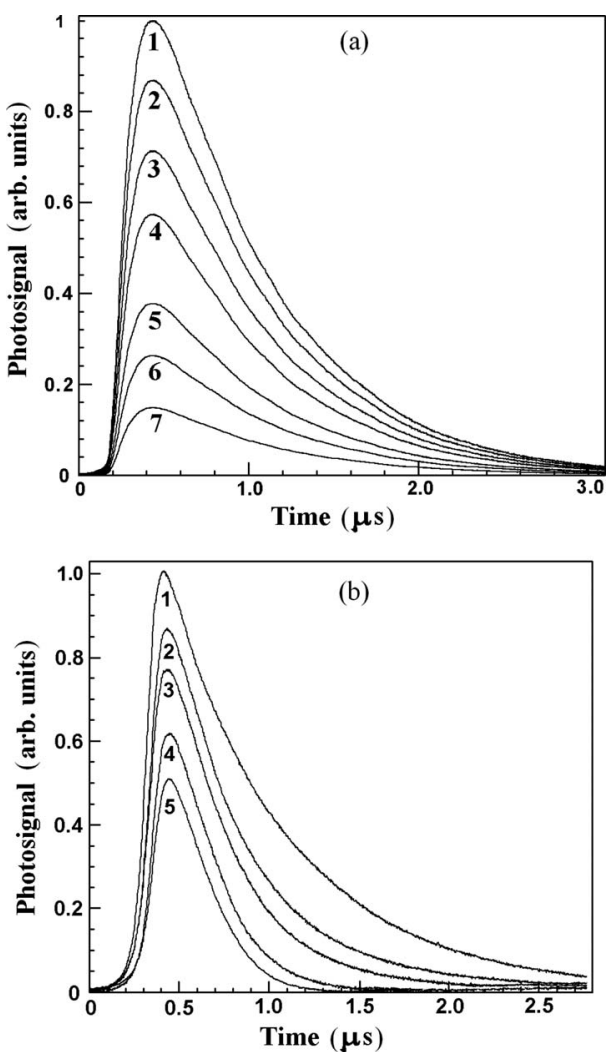

FIG. 4. PS from $\mathrm{PbTe} p$ - $n$ junction structures as a function of temperature. (a) TDJ: (1) 90, (2) 100, (3) 120, (4) 140, (5) 160, (6) 170, and (7) $180 \mathrm{~K}$. (b) IJ: (1) 90, (2) 100, (3) 110, (4) 120, and (5) $140 \mathrm{~K}$

This effect was induced due to generation of nonequilibrium electron-hole pairs in the top $2-3-\mu \mathrm{m}$-thick layer, their consequent diffusion toward a $p-n$ junction and separation by junction's built-in field.

This research was supported in part by IMD and NATO (CLG Grant No. 983122).

${ }^{1}$ Lead Chalcogenides. Physics and Applications, edited by D. Khokhlov (Taylor \& Francis, New York, 2003).

${ }^{2}$ A. Rogalski, Prog. Quantum Electron. 27, 59 (2003).

${ }^{3}$ A.V. Butenko, V. Sandomirsky, R. Kahatabi, Z. Dashevsky, V. Kasiyan, and Y. Schlesinger, Phys. Rev. Lett. 100, 057603 (2008).

${ }^{4}$ M. P. Dariel, Z. Dashevsky, A. Jarashneli, S. Shusterman, and A. Horowitz, J. Cryst. Growth 234, 164 (2002).

${ }^{5}$ Z. Dashevsky, V. Kasiyan, E. Mogilko, A. Butenko, R. Kahatabi, S. Genikhov, V. Sandomirsky, and Y. Schlesinger, Thin Solid Films 516, 7065 (2008).

${ }^{6}$ B. A. Volkov, L. I. Ryabova, and D. R. Khokhlov, Phys. Usp. 45, 819 (2002).

${ }^{7}$ A. Butenko, R. Kahatabi, E. Mogilko, R. Strul, V. Sandomirsky, Y. Schlesinger, Z. Dashevsky, V. Kasiyan, and S. Genikhov, J. Appl. Phys. 103, 024506 (2008).

${ }^{8} \mathrm{H}$. Zogg, in Lead Chalcogenides. Physics and Applications, edited by D. Khokhlov (Taylor \& Francis, New York, 2003), p. 587.

${ }^{9}$ A. N. Veis, Z. M. Dashevsky, and M. P. Rulenko, Sov. Phys. Semicond. 24, 76 (1990).

${ }^{10}$ A. Othonos, J. Appl. Phys. 83, 1789 (1998). 